\title{
GREEN SUPPLY CHAIN - BARRIERS AND BENEFITS OF IMPLEMENTING THE NEW MANAGEMENT STRATEGY - ANALYSIS OF THE EMPIRICAL RESEARCH
}

\author{
BLANKA TUNDYS \\ University of Szczecin, Faculty of management and Economics of Services, POLAND \\ e-mail: blanka.tundys@usz.edu.pl
}

RECEIVED
ACCEPTED
JEL
CLASSIFICATION

KEYWORDS management, green supply chain, barriers, benefits, drivers

ABSTRACT The point of view of the considerations shows the main goal was to show the barriers, benefits, and motivators for taking action to build a new management strategy namely the green supply chain. To realize of the aims was used literature analysis, which let to the selections of the extracted factors, and their verifications were based on empirical research conducted in two industries: food and clothing manufacturers. The catalog of factors is the basis for consideration and recommendations for organizations and supply chains, what elements to avoid, or which ones may be a problem in creating the green supply chain, and on the contrary, and to shows they will be motivating for the implementation of the new business strategy.

\section{Introduction and problem description}

Interest in the area of the green supply chain and its management has been observed since the 1990s. The evolution of the chain's assumptions and the support of trends in tackling the negative environmental impacts of economic processes contribute to the implementation of the new business strategy in the economy. The rapid industrialization of supply chains means that ecological effects are becoming increasingly problematic. Economic 
decision-making, by excluding the environmental interest, can contribute to environmental degradation, global warming, increased greenhouse gas emissions, and depletion of resources. There is no doubt that a holistic approach is needed to implement environmental goals in the supply chain, as well as the deployment of proenvironmental solutions already at the product conceptualization (and chain) stage, design, processing, assembly, storage, packaging, transportation, as well as collection, recycling, reuse, recycling and re-introduction into the economy. Activities cover both products and their packaging, and refer to all processes that take place within the supply chain. Such an approach to the problem contributes to growing interest in the green supply chain. Achieving competitive advantage requires also changes in the supply chain, traditionally understood relationships, scope, and paradigms are no longer sufficient to meet the needs of both customers and the market trends and requirements of competitors. Balancing environmental, economic and social goals contributes to building the foundations of green and sustainable supply chain management (Luthra, Qadri, Garg, Haleem, 2014). The paradigm of the green supply chain is based on the environmental and economic aspects that underpin its construction and operation. Joining the "green" into the supply chain contributes to the environmental and management implications of chain management. The goal of managing the green supply chain is to reduce waste and pollution by incorporating environmental thinking in product design (and packaging) and end-of-life management (Rehman, Shrivastava, 2011). The most important motivators for engaging an organization and reorienting its actions to implement green practices are: cost reduction and profit maximization, which also fosters competitiveness. These practices must involve all actors in the chain, suppliers, manufacturers, and customers. The cooperation of suppliers with partners and customers and producers can lead to better strategic and competitive position if environmental management is implemented in a cost effective manner (Vachon, Klassen, 2006). There is no doubt that the new management strategy is intended to help reduce negative environmental impacts and improve the efficiency of the supply chain (Seuring, Muller, 2008). It is therefore important to identify the barriers and benefits that new solutions bring to supply chain management. It should be pointed out that the presented results provide valuable information on the identified barriers and benefits in companies operating in Poland, as well as give the opportunity to compare with solutions indicated in the world literature. This is also a hint of what to look out for to turn traditional chains into greener ones.

\section{Litepature review}

The implementation of green supply chain management affects both barriers and benefits. Drivers forces are motivating factors for organizations, and barriers make it difficult to implement a new business model (Jain, Sharma, 2014). It is important to both understand the essence of both occurring, often parallel elements, and be able to take appropriate action to counter the hindrances and to achieve as many positive elements as possible. Green supply chain management refers to all processes that take place in the supply chain. Despite the need to incur high initial costs and investments, the efforts are aimed at improving the quality of processes, products, and increasing customer satisfaction. Green supply chain management can be defined as: integration of environmental thinking into the framework of supply chain management, which includes: product design, materials sourcing, and selection, manufacturing processes delivery of the final product after its useful life (Srivastava, 2007). According to Zhu and Sarkis (2006) shows that processes of the GrSCM have trend to close the loop from suppliers, to manufacturers, to customers and reverse logistics. In order to improve the environmental performance of suppliers and customers, it is important to integrate environmental issues into supply chain management (Lee, Klassen, 2008). Supply chain management is understood to have motivating factors and barriers. On the basis of literature one can point to the 
Tahle 1. Barriers, drivers and benefits for the green supply chain management - selected criterion for the empirical research

\begin{tabular}{|c|c|}
\hline Barriers & Drivers \\
\hline Increase in charges for waste disposal & Supporting the principles of sustainable development \\
\hline Increase in financial outlays & Development of modern logistics \\
\hline Increase in energy consumption & \multirow{2}{*}{ Investment recovery (sales) of excess stocks/materials } \\
\hline Stock up & \\
\hline Increase in investment & \multirow{2}{*}{ Designing products with reduced material energy consumption } \\
\hline Increase in operating costs & \\
\hline Increase in training costs & \multirow{2}{*}{$\begin{array}{l}\text { Designing products for reuse, recycling, material recovery, } \\
\text { components }\end{array}$} \\
\hline Material cost increase & \\
\hline The increase in costs for the purchase of environmentally friendly materials & \multirow{2}{*}{$\begin{array}{l}\text { Product design to avoid or reduce the use of hazardous } \\
\text { products and/or their manufacturing process }\end{array}$} \\
\hline Increased requirements for suppliers & \\
\hline Requirement of "green" investment & \multirow{2}{*}{$\begin{array}{l}\text { Collaboration at various levels and in areas to improve the } \\
\text { environment }\end{array}$} \\
\hline The need for close cooperation in the chain & \\
\hline No approval from employees & Comprehensive environmental quality management \\
\hline No demand & Implementation of audit programs \\
\hline No customer acceptance (cost increase) & Entering new markets \\
\hline \multicolumn{2}{|l|}{ Benefits } \\
\hline Increased use of "alternative" energy sources & Reduction of solid waste \\
\hline Improve the image of your business/supply chain & Fall in stocks \\
\hline Increase the efficiency of processes in the chain & Decrease in the cost of materials purchases \\
\hline Increase employee involvement in implementing environmental & Decline in consumption/harmful/hazardous materials \\
\hline Increased customer satisfaction & The decrease in material costs \\
\hline Increase in the amount of goods delivered on time & Reduce the frequency of environmental accidents \\
\hline Increase in customer satisfaction & Reduction of waste charges \\
\hline Increase in profits & Reduce energy costs \\
\hline Increased productivity of processes in the chain (including logistical processes) & Reducing the fee for waste (pollution related) \\
\hline Improving energy efficiency & Reduction of fees for ecological disasters \\
\hline Improvement of the company's environmental situation & Reduce energy costs \\
\hline Improved operating performance in the chain & Reduction of waste charges \\
\hline Improved capacity utilization & Reduction of charges for waste released \\
\hline Improving the quality of processes/products & Reduction of charges for environmental accidents \\
\hline Increasing the rate of decline of pollutants and waste & Supplier risk management \\
\hline Falling energy consumption & Trust suppliers \\
\hline Reduction of pollutant emissions into the atmosphere & Flexibility \\
\hline Wastewater reduction & Better image \\
\hline
\end{tabular}

Source: own elaboration.

driving forces that contribute to the implementation of new solutions. The most important ones include: increased intensity of competition, changing economic trends, government regulations, increasing consumer awareness and pressure. There is a close link between driving forces, and economic performance and competitiveness (Rao, Holt, 2005). So far, however, a complete catalog of driving forces, barriers and benefits of greening both in the chain as well as in the single link has not been established. Green supply chain management is based in principle on green procurement, procurement, production, storage, distribution, packaging and transport, green design and green operations (manufacturing and remanufacturing, reverse logistics, waste management) (Srivastava, 2007), 
Under which it is important to implement the principles of environmental management, redefine the concept of supply chain, use of recycling and remanufacturing processes, and change the performance measurement system (Beamon, 1999). The catalog of barriers and opportunities can be greatly expanded depending on the specificity of the organization, chain or geographic aspect, the issues are broadly described in the literature of the subject. The main sources of literature include: W. Niemann, T. Kotze, F. Adamo (2016), H. Walker, L. Di Sisto and D. McBain (2008), E. Ojo, C. Mbowa and E.T. Akinlabi (2014), S. Luthra et al. (2014), E. Nikbakhsh (2009). P. Srivastav and M.K. Gaur (2015). M. Javaid, M. Shoeb (2015), A. Diabat, K. Govindan (2011). Literature studies and pilot studies have allowed the selection of elements for the study, which is presented in Table 1.

\section{Research goals and questions}

The research objectives of the discussion are based on identifying and verifying motivators, barriers and benefits of greening processes and supply chain links based on literary analysis and empirical research. The most important issues to be addressed in the discussion include:

- what are the motivating factors and barriers to the implementation of green practices in the supply chain in the research organizations,

- which one has the greatest impact on the creation of the green supply chain.

\section{Solution methodology and data collection}

The paper was prepared using the method of critical analysis of the literature (Cotrell, 2011). On this basis were selected the criteria catalog for the drivers, barriers and benefits of the implementation and creating the green supply chain management (Table 1). The data was used to create a questionnaire. The empirical studies were prepared in the form of questionnaire (Lydeard, 1995), then were selected a sample of the research and conducted the empirical studies on a selected group of the entities. Criteria selection took place after pre-selection and expert investigation. It was agreed that the factors included in the questionnaire will be taken into account in the questionnaire. The next phase of the survey was followed by an analysis and interpretation of the data. The survey using a questionnaire was conducted throughout of Poland, using the CATI method, in connection with an extensive questionnaire and the need to sacrifice more time to fill it, interviewers performed them for 3 months. The survey was directed to the Food and clothing Industry. On the basis of randomly selected study sample, were examined 222 companies. Other limitations of the study are: the number of employees between 50 and 99 person and responding to the questionnaire employees are: middle to senior levels of management experience, for example supply chain manager, logistics manager, head of logistics or supply chain, procurement and purchasing manager.

\section{Results and discussion}

By analyzing the research conducted, one can point out that in most cases classification of elements as barriers, opportunities or motivators coincides with respondents' responses. It is also worth noting that for some respondents some factors are irrelevant when creating a green supply chain, and that, regardless of the industry, the results are practically overlapping. 
Table 2. Results of the empirical research

\begin{tabular}{|c|c|c|c|c|c|c|}
\hline \multirow{3}{*}{ Factors } & \multicolumn{6}{|c|}{ Percent } \\
\hline & \multicolumn{3}{|c|}{ clohting industry; $n=68$} & \multicolumn{3}{|c|}{ food industry; $n=154$} \\
\hline & barrier & benefits & neutral & barrier & benefits & neutral \\
\hline 1 & 2 & 3 & 4 & 5 & 6 & 7 \\
\hline Increase in charges for waste disposal & 95.59 & 0.00 & 4.41 & 95.45 & 0.00 & 4.55 \\
\hline Increase in financial outlays & 100.00 & 0.00 & 0.00 & 100.00 & 0.00 & 0.00 \\
\hline Increase in energy consumption & 60.29 & 0.00 & 39.71 & 60.39 & 0.00 & 39.61 \\
\hline Increased use of "alternative" energy sources & 45.59 & 30.88 & 23.53 & 44.16 & 32.47 & 23.38 \\
\hline Increased productivity of processes in the chain (including logistical processes) & 0.00 & 94.12 & 5.88 & 0.00 & 94.16 & 5.84 \\
\hline Increase the efficiency of processes in the chain & 0.00 & 97.06 & 2.94 & 0.00 & 97.40 & 2.60 \\
\hline Increase employee involvement in implementing environmental, & 0.00 & 63.24 & 36.76 & 0.00 & 62.99 & 37.01 \\
\hline Increased customer satisfaction & 0.00 & 86.76 & 13.24 & 0.00 & 86.36 & 13.64 \\
\hline Stock up & 83.82 & 0.00 & 16.18 & 83.77 & 0.00 & 16.23 \\
\hline Increase in investment & 67.65 & 0.00 & 32.35 & 66.23 & 0.00 & 33.77 \\
\hline Increase in operating costs & 45.59 & 5.88 & 48.53 & 44.16 & 5.84 & 50.00 \\
\hline Increase in training costs & 100.00 & 0.00 & 0.00 & 100.00 & 0.00 & 0.00 \\
\hline The increase in costs for the purchase of environmentally friendly materials & 32.35 & 0.00 & 67.65 & 31.82 & 0.00 & 68.18 \\
\hline Material cost increase & 92.65 & 0.00 & 7.35 & 92.86 & 0.00 & 7.14 \\
\hline Increase in profits & & 94.12 & 5.88 & & 94.16 & 5.84 \\
\hline Improve the image of your business/supply chain & 0.00 & 94.12 & 5.88 & 0.00 & 94.16 & 5.84 \\
\hline Improving energy efficiency & 0.00 & 60.29 & 39.71 & 0.00 & 59.74 & 40.26 \\
\hline Improvement of the company's environmental situation & 0.00 & 35.29 & 64.71 & 0.00 & 35.06 & 64.94 \\
\hline Improved operating performance in the chain & 0.00 & 11.76 & 88.24 & 0.00 & 11.69 & 88.31 \\
\hline Improved capacity utilization & 0.00 & 89.71 & 10.29 & 0.00 & 88.96 & 11.04 \\
\hline Improving the quality of processes/products & 0.00 & 57.35 & 42.65 & 0.00 & 60.39 & 39.61 \\
\hline Increasing the rate of decline of pollutants and waste & 0.00 & 51.47 & 48.53 & 0.00 & 53.25 & 46.75 \\
\hline Increase the quantity of goods delivered on time & 0.00 & 27.94 & 72.06 & 0.00 & 28.57 & 71.43 \\
\hline Falling energy consumption & 0.00 & 58.82 & 41.18 & 0.00 & 57.79 & 42.21 \\
\hline Reduction of pollutant emissions into the atmosphere & 0.00 & 94.12 & 5.88 & 0.00 & 94.16 & 5.84 \\
\hline Wastewater reduction & 0.00 & 70.59 & 29.41 & 0.00 & 70.78 & 29.22 \\
\hline Reduction of solid waste & 0.00 & 76.47 & 23.53 & 0.00 & 77.92 & 22.08 \\
\hline Fall in stocks & 0.00 & 69.12 & 30.88 & 0.00 & 0.00 & 0.00 \\
\hline Decrease in the cost of materials purchases & 0.00 & 94.12 & 5.88 & 0.00 & 68.18 & 31.82 \\
\hline Decline in consumption/harmful/hazardous materials & 0.00 & 38.24 & 61.76 & 0.00 & 94.16 & 5.84 \\
\hline The decrease in material costs, & 0.00 & 23.53 & 76.47 & 0.00 & 38.96 & 61.04 \\
\hline Reduce the frequency of environmental accidents & 0.00 & 54.41 & 45.59 & 0.00 & 23.38 & 76.62 \\
\hline Reducing the fee for waste (pollution related) & 0.00 & 63.24 & 36.76 & 0.00 & 52.60 & 47.40 \\
\hline Reduction of fees for ecological disasters & 0.00 & 67.65 & 32.35 & 0.00 & 64.29 & 35.71 \\
\hline Reduce energy costs & 0.00 & 47.06 & 52.94 & 0.00 & 66.23 & 33.77 \\
\hline Reduction of waste charges & 0.00 & 35.29 & 64.71 & 0.00 & 48.70 & 51.30 \\
\hline Reduction of charges for waste released & 0.00 & 41.18 & 58.82 & 0.00 & 35.71 & 64.29 \\
\hline Reduction of charges for environmental accidents & 0.00 & 42.65 & 57.35 & 0.00 & 41.56 & 58.44 \\
\hline Increased requirements for suppliers & 57.35 & 0.00 & 42.65 & 0.00 & 42.86 & 57.14 \\
\hline Requirement of "green" investment & 61.76 & 0.00 & 38.24 & 57.79 & 0.00 & 42.21 \\
\hline The need for close cooperation in the chain & 22.06 & 32.35 & 45.59 & 61.69 & 0.00 & 38.31 \\
\hline No approval from employees & 38.24 & 0.00 & 61.76 & 22.73 & 33.12 & 44.16 \\
\hline No demand & 69.12 & 0.00 & 30.88 & 38.31 & 0.00 & 61.69 \\
\hline
\end{tabular}




\begin{tabular}{|c|c|c|c|c|c|c|}
\hline 1 & 2 & 3 & 4 & 5 & 6 & 7 \\
\hline No customer acceptance (cost increase) & 55.88 & 0.00 & 44.12 & 70.78 & 0.00 & 29.22 \\
\hline Supplier risk management & 14.71 & 26.47 & 58.82 & 57.14 & 0.00 & 42.86 \\
\hline Trust suppliers & 0.00 & 70.59 & 29.41 & 15.58 & 25.32 & 59.09 \\
\hline Flexibility & 0.00 & 70.59 & 29.41 & 0.00 & 70.78 & 29.22 \\
\hline Better image & 0.00 & 58.82 & 41.18 & 0.00 & 58.44 & 41.56 \\
\hline Supporting the principles of sustainable development & 0.00 & 70.59 & 29.41 & 0.00 & 70.78 & 29.22 \\
\hline Development of modern logistics & 0.00 & 67.65 & 32.35 & 0.00 & 66.88 & 33.12 \\
\hline Investment recovery (sales) of excess stocks/materials & 0.00 & 16.18 & 83.82 & 0.00 & 18.18 & 81.82 \\
\hline Designing products with reduced material energy consumption & 0.00 & 10.29 & 89.71 & 0.00 & 11.69 & 88.31 \\
\hline Designing products for reuse, recycling, material recovery, components & 0.00 & 8.82 & 91.18 & 0.00 & 9.74 & 90.26 \\
\hline $\begin{array}{l}\text { Product design to avoid or reduce the use of hazardous products and/ } \\
\text { or their manufacturing process }\end{array}$ & 0.00 & 8.82 & 91.18 & 0.00 & 9.74 & 90.26 \\
\hline Collaboration at various levels and in areas to improve the environment & 0.00 & 22.06 & 77.94 & 0.00 & 21.43 & 78.57 \\
\hline Comprehensive environmental quality management & 0.00 & 16.18 & 83.82 & 0.00 & 16.23 & 83.77 \\
\hline Implementation of audit programs & 8.82 & 7.35 & 83.82 & 8.44 & 7.79 & 83.77 \\
\hline Entering new markets & 0.00 & 16.18 & 83.82 & 0.00 & 16.23 & 83.77 \\
\hline
\end{tabular}

Source: own elaboration.

Interestingly, there is a lack of demand in the clothing industry is a barrier, which is not a problem for the food industry. In other cases, respondents respond similary. It is clear that certain criteria in literature describe as barriers are barriers to the organization, which were examinated, as well as opportunities or motivators. The interesting result is that for the most organizations, drivers are considered it indifferent to creating a green supply chain. This means that actions need to be taken to reduce the number of barriers and costs associated with them, and the implemented solutions will contribute to increasing the benefits, both in terms of their numbers and percentage of respondents who take the actions they consider beneficial, and not, for example, affecting the creation and operation of the supply chain.

\section{Limitations}

Definitely a limiting factor, both considerations as well as interpretations and general conclusions are the selected sectors, the number involved in the study and the size of the enterprise. One should ask yourself whether in other conditions and in other industries the results would appear in a similar way.

\section{Conclusions}

By analyzing the empirical research conducted, it is important to point out that the identified factors indicating the benefits, barriers or motivators for undertaking green supply chain construction activities in a large part were confirmed by the respondents. The biggest barriers are Increase in charges for waste disposal, Increase in financial outlays, Increase in training costs, Material cost increase. As benefits it could be point: Decrease in the cost of materials purchases, Reduction of pollutant emissions into the atmosphere, Increase in profits, Improve the image of your business/supply chain, Increased customer satisfaction, Increased productivity of processes in the chain (including logistical processes), Increase the efficiency of processes in the chain. An interesting element of the discussion is the indication that some of the respondents recognize the presented factors as completely 
indifferent. This means that they do not have an impact on the creation and operation of the green supply chain. Recommendations may refer to further education and training, which will help to identify benefits and barriers better to offset the number of neutral factors that respondents do not consider relevant and which affect the development of the green supply chain. The study also showed that both the number and the range of benefits are definitely greater than the potential barriers. Motivators should be supported and benefits should be emphasized, and costs and barriers to the introduction of the green supply chain should be eliminated.

\section{Acknowledgments}

This paper is a part of a project financed by the National Science Centre granted on the basis of the decision DEC-2013/09/B/HS4/02707.

\section{Referenences}

Beamon, B.M. (1999). Designing the green supply chain. Logistics information management, 4 (12), 332-342.

Cottrell, S. (2011). Critical thinking skills: Developing effective analysis and argument. Basingstoke: Palgrave Macmillan.

Diabat, A., Govindan, K. (2011). An analysis of the drivers affecting the implementation of green supply chain management. Resources, Conservation and Recycling, 6 (55), 659-667.

Jain, V.K., Sharma, S. (2014). Drivers affecting the green supply chain management adaptation: a review. IUP Journal of Operations Management, 1 (13), 54.

Javaid, M., Shoeb, M. (2015). International Journal of Advanced Technology in Engineering and Science, 3 (6), 2348-7550, p. 129. Retrieved from: www.ijates.com.

Lee, S.Y., Klassen, R.D. (2008). Drivers and enablers that foster environmental management capabilities in small- and medium-sized suppliers in supply chains. Production and Operations management, 6 (17), 573-586.

Luthra, S., Kumar, V., Kumar, S., Haleem, A. (2011). Barriers to implement green supply chain management in automobile industry using interpretive structural modeling technique: An Indian perspective. Journal of Industrial Engineering and Management, 2 (4), 231-257.

Luthra, S., Qadri, M.A., Garg, D., Haleem, A. (2014). Identification of critical success factors to achieve high green supply chain management performances in Indian automobile industry. International Journal of Logistics Systems and Management 1, 2 (18), 170-199.

Lydeard, S (1995). The questionnaire as a research tool. Family Practice, 1 (8), 84-91.

Niemann, W., Kotze, T., Adamo, F. (2016). Drivers and barriers of green supply chain management implementation in the Mozambican manufacturing industry. Journal of Contemporary Management, 1 (13), 977-1013.

Nikbakhsh, E. (2009). Green supply chain management. In: Supply chain and logistics in national, international and governmental environment (pp. 195-220). Physica-Verlag HD.

Ojo, E., Mbowa, C., Akinlabi, E.T. (2014). Barriers in implementing green supply chain management in construction industry. In: Proceedings of the 2014 International Conference on Industrial Engineering and Operations Management (IEOM) (pp. 7-9).

Rao, P., Holt, D. (2005). Do green supply chains lead to competitiveness and economic performance? International journal of operations \& production management, $9(25), 898-916$.

Rehman, M.A.A., Shrivastava, R.L. (2011). An innovative approach to evaluate green supply chain management (GSCM) drivers by using interpretive structural modeling (ISM). International Journal of Innovation and Technology Management, 2 (8), 315-336.

Seuring, S., Müller, M. (2008). From a literature review to a conceptual framework for sustainable supply chain management. Journal of cleaner production, 15 (16), 1699-1710.

Srivastav, P., Gaur, M.K. (2015). Barriers to Implement Green Supply Chain Management in Small Scale Industry using Interpretive Structural Modeling Technique - A North Indian Perspective. European Journal of Advances in Engineering and Technology, $2(2), 6-13$.

Srivastava, S.K. (2007). Green supply-chain management: a state-of-the-art literature review. International journal of management reviews, 1 (9), 53-80. 
Vachon, S., Klassen, R.D. (2006). Green project partnership in the supply chain: the case of the package printing industry. Journal of Cleaner production, 6 (14), 661-671.

Walker, H., Di Sisto, L., McBain, D. (2008). Drivers and barriers to environmental supply chain management practices: Lessons from the public and private sectors. Journal of purchasing and supply management, 1 (14), 69-85.

Zhu, Q., Sarkis, J. (2006). An inter-sectoral comparison of green supply chain management in China: drivers and practices. Journal of cleaner production, 5 (14), 472-486.

Cite this article aS: Tundys, B. (2018). Green supply chain - barriers and benefits of implementing the new management strategy analysis of the empirical research. European Journal of Service Management, 2 (26), 293-300. DOI: 10.18276/ejsm.2018.26-36. 